Servicio de Medicina Interna Hospital San José, Santiago,

Chile.

Universidad de Santiago de Chile.

Recibido el 17 de junio de 2014 aceptado el 9 de octubre de 2014.

Correspondencia a: Anne-Marie Chassin-Trubert Contreras

Dirección: Cirujano Guzmán 70, Dpto. 1303, Providencia, Santiago. annechassin@gmail.com

\title{
Síndrome de la bolsa de orina púrpura: un fenómeno inusual y muy llamativo
}

\author{
ANNE-MARIE CHASSIN-TRUBERT C.
}

\section{Purple urine bag syndrome. Report of one case}

\begin{abstract}
Purple urine bag syndrome is an uncommon but particularly striking phenomenon observed in people with urinary catheters and co-existent urinary tract infections. A chemical reaction between plastic and certain bacterial enzymes results in an intense purple urine color. We report a 72 year-old male with a cystostomy. A purple coloration of his urinary drainage bag and tubing was noted in the context of a urinary tract infection caused by Citrobacter freundii.

(Rev Med Chile 2014; 142: 1482-1484)
\end{abstract}

Key words: Purple urine bag syndrome; Urinary catheters; Urinary tract infections.

E 1 síndrome de la bolsa de orina púrpura (PUBS) es una condición poco frecuente, descrita por primera vez por Barlow y Dickson en $1978^{1}$, que se presenta principalmente en pacientes ancianos con múltiples enfermedades crónicas, portadores de sonda vesical, en los cuales coexiste una infección del tracto urinario por determinadas bacterias productoras de sulfatasas y fosfatasas ${ }^{2}$, capaces de reaccionar químicamente con la orina y el material plástico de la bolsa colectora y de la sonda vesical, fabricados con cloruro de polivinilo (PVC), produciendo un color purpúrico intenso de la orina ${ }^{3}$.

Los factores de riesgo para presentar PUBS son el sexo femenino, la edad avanzada, el uso de catéter urinario permanente, la postración, la constipación crónica, la enfermedad renal crónica y la dieta hiperproteica, factores que se relacionan con la disminución del tránsito intestinal, sobrecrecimiento bacteriano y aumento de la cantidad de indol en el intestino ${ }^{4-7}$.

En su patogenia está involucrado el triptófano aportado por la dieta, el cual es degradado por las bacterias de la flora intestinal produciendo indol. Este último es absorbido, pasando a la circulación portal y, en el hígado, es transformado en indoxil sulfato o indican, el cual es excretado por la orina. El indoxil sulfato, en presencia de la enzima bacteriana indoxil-sulfatasa, es hidrolizado a indoxil. En un ambiente básico (orina alcalina) y poco oxigenado, se producen pigmentos de indirrubina (rojo) e índigo (azul), los cuales al interactuar con los materiales sintéticos del catéter y la bolsa urinaria, precipitan en la orina otorgándole una coloración púrpura característica (Figura 1). La decoloración depende del recuento de colonias bacterianas y de la concentración de indoxil sulfato.

Las bacterias productoras de fosfatasas y sulfatasas poseen, además, la enzima ureasa, que alcaliniza la orina creando un ambiente básico favorecedor del cambio de color de la orina. Entre las bacterias mayormente implicadas en este fenómeno, se encuentran: Escherichia coli; Citrobacter koseri, freundii y diversus; Enterococcus agglomerans, avium, faecalis y cloacae; Klebsiella pneumoniae; Morganella morganii; Providencia stuartii y rettgeri; Proteus mirabilis y vulgari; Pseudomona aeruginosa ${ }^{8}$.

El PUBS se considera una condición benigna, ya que la orina se aclara y vuelve a su color original al instaurar un tratamiento antibiótico adecuado que resuelva la infección urinaria coexistente ${ }^{3}$.

Se presenta el siguiente caso de PUBS con la finalidad de comunicar un fenómeno poco frecuente y muy llamativo, capaz de causar preocupación e inquietud tanto al paciente y su cuidador, como al equipo de salud enfrentado a pacientes geriátricos. 


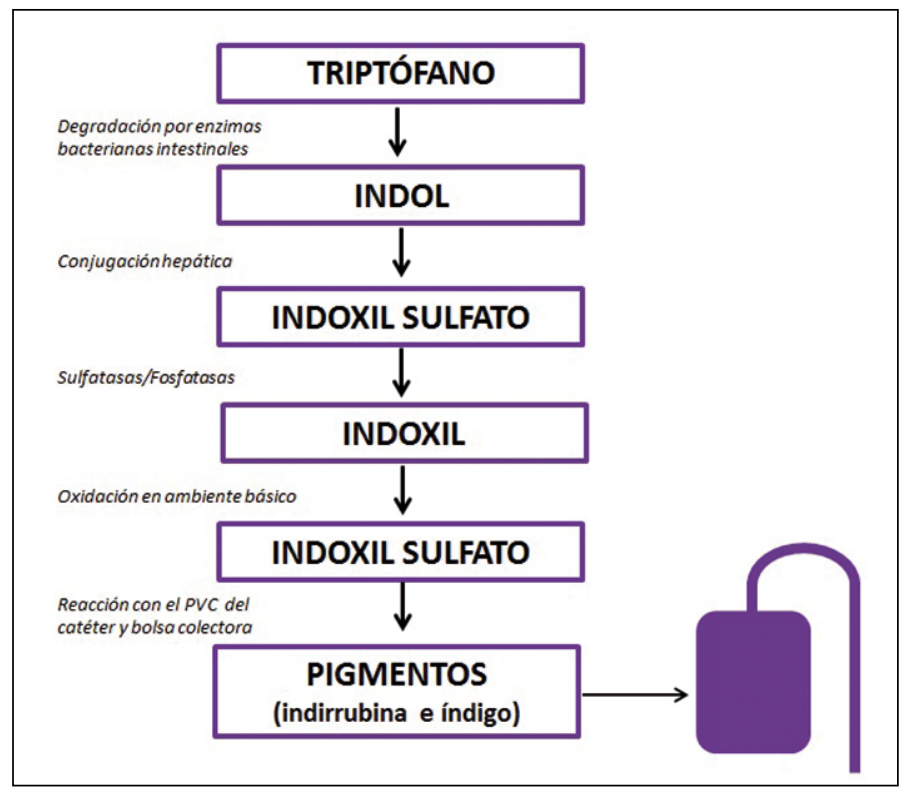

Figura 1. Ruta bioquímica de la conversión de triptófano en índigo e indirrubina.

\section{Presentación del caso}

Paciente masculino de 72 años con antecedentes de cardiopatía coronaria, insuficiencia renal crónica en hemodiálisis hace 5 años y uropatía obstructiva, portador de una cistostomía hace 5 años, fue hospitalizado en el servicio de medicina interna para realizar un cambio de catéter de hemodiálisis, en contexto de catéter disfuncional; sin embargo, a su ingreso llamó la atención la cistostomía que estaba en mal estado, objetivándose la presencia de orina de color púrpura en la bolsa colectora (Figura 2).

Dentro de los medicamentos que el paciente usaba en forma crónica, no destacó ninguno que pudiese relacionarse con el cambio de coloración de la orina.

$\mathrm{Al}$ examen físico, el paciente se encontraba en buenas condiciones generales, afebril, hemodinámicamente estable, con cistostomía in situ, funcionante, pero con signos de deficiente autocuidado, sucia y de muy mal olor.

Se solicitó un sedimento urinario que evidenció leucocitos 5-10 x campo [valor normal (VN): 1-5], abundantes bacterias y fosfatos amorfos abundantes x campo. En el examen de orina completo destacó el color y aspecto turbio, $\mathrm{pH}$ de 7,8 [VN: 4,5-8,0] y nitritos positivos. En el urocultivo se objetivó un recuento mayor a 100.000

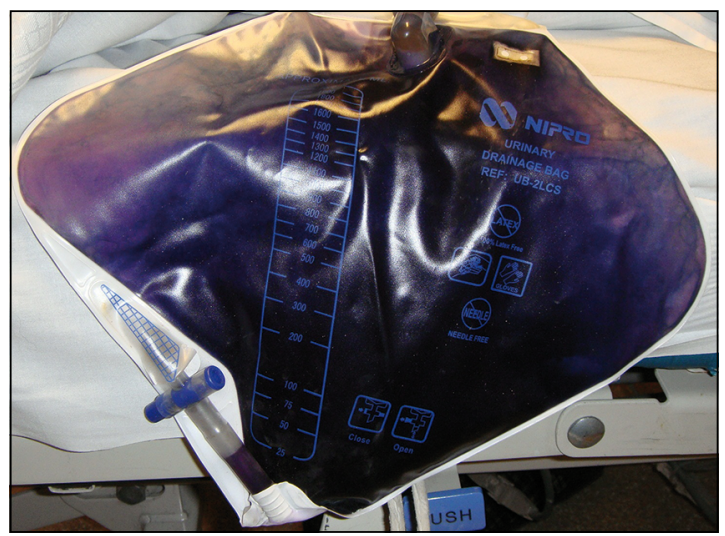

Figura 2. Orina de color púrpura en la bolsa colectora.

$\mathrm{UFC} / \mathrm{ml}$ de Citrobacter freundii resistente a cefadroxilo, ciprofloxacino y nitrofurantoína. Entre los exámenes de sangre, destacó una leucocitosis de $10.600 \mathrm{x} \mathrm{mm}^{3}$ [VN: 4.000-9.000], una PCR de $34 \mathrm{mg} / \mathrm{dL}$ [VN: 0-5] y una VHS de $54 \mathrm{~mm} / \mathrm{h}$ [VN: 2-10]. Se le realizó una ecografía prostática, procedimiento que fue técnicamente limitado por parcial distensión vesical, con un volumen al momento del estudio de $26 \mathrm{cc}$, en la cual no fue posible evaluar la glándula prostática. Se inició tratamiento antibiótico con ceftriaxona $2 \mathrm{~g} /$ día endovenoso y se solicitó evaluación por urología, 
quienes decidieron realizar un recambio de la cistostomía, en contexto de la infección urinaria y el aspecto mal cuidado de ésta.

Con el transcurso de los días, se observó un aclaramiento progresivo del color de la orina, retornando a su color natural tras 7 días de antibioterapia.

\section{Discusión}

Para que se produzca el cambio de coloración de la orina característico del PUBS se requiere la coexistencia de ciertas condiciones específicas: pacientes con múltiples comorbilidades, portadores de sonda vesical y que estén cursando con una infección del tracto urinario por determinados gérmenes. La coloración púrpura puede aparecer desde horas hasta días posteriores a la colocación del catéter urinario y se hace más intensa a medida que pasa el tiempo, sin realizar un recambio oportuno de la bolsa colectora de orina. Es interesante observar que la orina no es púrpura al ser colocada en otro recipiente estéril9.

La prevalencia exacta del PUBS es desconocida. La gran mayoría de las publicaciones son reportes de casos clínicos, no existiendo estudios con tamaños muestrales significativos. Se estima una prevalencia de $9,8 \%$ en pacientes con catéter urinario permanente ${ }^{10,11}$. No hay datos acerca de su prevalencia en Chile. Se trata de una condición benigna y, en general, los pacientes se mantienen clínicamente asintomáticos ${ }^{4}$. En efecto, para algunos autores, no sería necesario un tratamiento antibiótico agresivo, sino un buen manejo de la sonda vesical con un reemplazo prudente de ésta ${ }^{12}$.

La implicancia clínica del PUBS es equivalente a la de una infección urinaria y no cambia el pronóstico del paciente ${ }^{13}$. Si bien, la presencia de orina alcalina es una condición reportada en la mayoría de los estudios realizados, se han descrito algunos casos en que ante la presencia de altos niveles de sulfato de indoxil y una alta carga bacteriana se puede dar el fenómeno en orina ácida ${ }^{14}$. Para realizar un correcto diagnóstico diferencial, se debe tomar en cuenta la existencia de diversas condiciones que producen cambios en la coloración de la orina hacia un tinte azul-verdoso o púrpura, entre ellas la ingesta de alimentos con colorantes, el consumo de remolacha, tintes como el azul de metileno, compuestos que contienen yodo, medi- camentos como la amitriptilina, la indometacina y el exceso de vitamina $B$, así como ciertas patologías como la porfiria o el síndrome de Drummond o síndrome del pañal azul ${ }^{15-16}$.

\section{Referencias}

1. Barlow GB, Dickson JAS. Purple urine bags. Lancet 1978; 311: 220-1.

2. Harun NS, Nainar SK, Chong VH. Purple urine bag syndrome: a rare and interesting phenomenon. South Med J 2007; 100 (10): 1048-50.

3. Campbell SE, Izquierdo A, Campbell S, Erazo L, Calderón C. Síndrome de la bolsa de orina púrpura. Acta Med Colomb 2011; 36: 38-40.

4. Tang MW. Purple urine bag syndrome in geriatric patients. J Am Geriatr Soc 2006; 54 (3): 560-1.

5. Su FH, Chung SY, Chen MH, Sheng ML, Chen CH, Chen YJ, et al. Case analysis of purple urine-bag syndrome at a long-term care service in a community hospital. Chang Gung Med J 2005; 28 (9): 636-42.

6. Wang IK, Ho DR, Chang HY, Lin CL, Chuang FR. Purple urine bagsyndrome in a hemodialysis patient. Intern Med 2005; 44 (8): 859-61.

7. Mantani N, Ochiai H, Imanishi N, Kogure T, Terasawa $\mathrm{K}$, Tamura J. A case-control study of purple urine bag syndrome in geriatric wards. J Infect Chemother 2003; 9 (1): 53-7.

8. Dealler SF, Hawkey PM, Millar MR. Enzymatic degradation of urinary indoxyl sulfate by Providenciastuartii and Klebsiella pneumoniae causes the purple urine bag syndrome. J Clin Microbiol 1988; 26: 2152-6.

9. Gelasco AK, Raymond JR. Indoxyl sulfate induces complex redox alterations in mesangial cells. Am J Physiol Renal Physiol 2006; 290: F1551-8.

10. Hadano Y, Shimizu T, Takada S, Inoue T, Sorano S. An update on purple urine bag syndrome. Int J Gen Med 2012; 5 (1): 707-10.

11. Dealler SF, Belfield PW, Bedford M, Whitley AJ, Mulley GP. Purple urine bags. J Urol 1989; 142: 769-70.

12. Lee J. Images in clinical medicine. Purple urine. $\mathrm{N}$ Engl J Med 2007; 357 (13): e14.

13. Hussain AS, Haroon D. The purple urine bag syndrome. Am J Med 2009; 122 (10): e1-2.

14. Chung SD, Liao CH, Sun HD. Purple urine bag syndrome with acidic urine. Int J Infect Dis 2008; 12 (5): 526-7.

15. Tan CK, Wu YP, Wu HY, Lai CC. Purple urine bag syndrome. Can Med Assoc J 2008; 179: 491.

16. Raymond JR, Yarger WE. Abnormal urine color: Differential diagnosis. South Med J 1988; 81: 837-41. 